\title{
Synthesis and Characterization of Multi-Walled Carbon Nanotubes Decorated ZnO Nanocomposite
}

\author{
Eman, A. Mwafy ${ }^{a}$, M. Dawy ${ }^{a}$, A. Abouelsayed ${ }^{b}$, I. A. \\ Elsabbagh $^{\mathrm{c}}$ and M. M. Elfass ${ }^{\mathrm{c}}$ \\ ${ }^{a}$ Physical Chemistry Department, Inorganic Chemical \\ Industries and Mineral Resources Division. ${ }^{b}$ Spectroscopy \\ Department, Physics Division, National Research Centre, 33 \\ ElBohouth st. (fromer El Tahrir st.), Dokki, Giza, P.O. 12622 \\ and ${ }^{c}$ Chemistry Department, Faculty of Science, Al-Azhar \\ University, Cairo 11884, Egypt.
}

\begin{abstract}
W ULTI-WALLED carbon nanotubes decorated Zinc oxide (MWCNTs/ZnO) nanocomposites with ratio of (99: 1 wt \%) was prepared using sol gel method. Transmission Electron Microscope (TEM) and The X-ray diffraction pattern (XRD) showed that the MWCNTs/ZnO nanocomposites was synthesized with particle size ranging from $2-7 \mathrm{~nm}$ and crystalline size about $7 \mathrm{~nm}$. The Field Emission Scanning Electron Microscopy (FESEM) images demonstrate that $\mathrm{ZnO}$ had grown on the walls of MWCNTs were uniformed layer in the shape of thin film layer of nanospheres covering the surface of the tubes, also the energy dispersive X-ray spectrum (EDX) and Fourier Transformed Infrared spectroscopy (FTIR) prove the presence of $\mathrm{ZnO}$ without any impurities.
\end{abstract}

Keywords: MWCNT, MWCNTs/ZnO nanocomposites and Sol gel method.

One-dimensional (1D) nanostructure materials had attracted a great interest due to their incredible properties and high-potential technology applications in the synthesis of nanoscale devices ${ }^{(1)}$. Since their discovery in $1991^{(2)}$, carbon nanotubes (CNTs) are interesting 1D structure materials with high aspect ratio (diameter to length) that has unique mechanical, electronic and chemical properties ${ }^{(3)}$. So, CNTs have been attracted much attention over the past few years. Recently, CNTs-metal oxide based nanocomposite has a great attention due to their potential applications as active elements in a wide range applications including nanoelectronic and nano mechanical devices, super capacitors, energy storage materials, catalyst supports and sensors ${ }^{(4)}$.

The combination of the unique properties of both CNTs and semiconductor nanostructures is creating a new class of nanocomposite materials that opens a new broad range of applications in different areas of science ${ }^{(5,6)}$. There are a lot of researches about the growth of metal oxide nanoparticles using CNT as 1D template. $\mathrm{ZnO}, \mathrm{TiO}_{2}, \mathrm{SnO}_{2}, \mathrm{CdS}, \mathrm{CdSe}$, and $\mathrm{CdTe}$ nanoparticles decorated on the wall surface of CNTs are attractive semiconductor due to their incredible 
properties that make them candidate in several applications as photoelectrochemical solar cell, gas sensors and photo-detectors ${ }^{(7)}$.

There is a fact that Zinc Oxide $(\mathrm{ZnO})$, as an oxide, presents as a semiconductor with a direct wide band gap $(3.37 \mathrm{eV})$, and a large exciton binding energy of $60 \mathrm{meV}$ at room temperature ${ }^{(8)}$, so it was expected that when CNTs was coated with $\mathrm{ZnO}$, they would be formed a composite with a promising properties coupling the merits of both.

Various synthetic strategies based on chemical and physical processes to obtain on a promising nanocomposite have been reported. With the recent advance in the design of CNTs composites, sol gel method can be used to deposit a variety of materials including oxides and metals on the surface of CNTs with a small diameter at rather low temperatures.

In this paper, MWCNTs/ZnO nanocomposite with weight ratio of (99: $1 \mathrm{wt}$ $\%)$ was prepared by a sol-gel method and its properties were investigated by using Transmission Electron microscope (TEM), X-ray diffraction pattern (XRD), Fourier Transformed Infrared spectroscopy (FTIR) and The Field Emission scanning electron microscopy (SEM) with the aid of energy dispersive $\mathrm{X}$-ray spectrum (EDX)

\section{Experimental}

\section{Reagents and chemicals}

Multi-walled carbon nanotubes (MWCNT) were previously prepared by the Chemical Vapour Deposition (CVD) method with diameter of around $25 \mathrm{~nm}$, zinc nitrate dihydrate were purchased from Sigma-Aldrich. Citric acid was purchased from Alnasr for Chemicals Company. Nitric acid (65\%), HCl, poly ethylene glycol and ammonium solution were obtained from Merck. All chemical were used without any purification.

\section{Synthesis of MWCNTs/ZnO (99:1 wt\%) nanocomposite}

A typical experimental procedure was followed. Firstly, the MWCNTs were purified from any remaining catalyst by washing with $5 \mathrm{M} \mathrm{HCl}$ solution, then the surface of tubes was functionalized and opened by oxidation with nitric acid solution (65\%) and refluxing for $6 \mathrm{hr}$, then the treated MWCNTs were washed with distilled water several times until the $\mathrm{pH}$ reached 7 and dried at $90^{\circ} \mathrm{C}$ for an overnight. Secondly $1 \mathrm{wt} \%$ of $\mathrm{ZnNO}_{3}$ was dissolved in $10 \mathrm{ml}$ of distilled water, followed by adding to a solution of acid treated MWCNTs dispersed in distilled water using ultrasound bath for $2 \mathrm{hr}$, then $0.5 \mathrm{gm}$ of citric acid and $5 \mathrm{ml}$ of ethylene glycol solution were added and the mixture was stirred for another 2 $\mathrm{hr}$ at room temperature then dropwise of ammonia solution was added until the $\mathrm{PH}$ reached to 7 then the temperature was raised up to $80^{\circ} \mathrm{C}$ to evaporate the solvent. Finally, the mixture was dried at $80^{\circ} \mathrm{C}$ then calcinated at $350^{\circ} \mathrm{C}$ for 4 hr.

Egypt. J. Chem. 59, No. 6 (2016) 


\section{Characterization techniques}

The size and shape of $\mathrm{CNT} / \mathrm{ZnO}$ nanocomposite were observed on a high resolution transmission electron microscope (HRTEM) JEOL-JEM-1011, Japan. Images were recorded at a rate of $200 \mathrm{kV}$. For each sample, low concentration of suspension dispersion was deposited on a carbon copper grid and left to dry at room temperature. Field emission scanning electron microscope (FE-SEM) on a Quanta FEG 250 (Czech Republic) was used to investigate the morphology analysis cooped with Energy Dispersive X-ray spectroscopy analysis (TEAM -EDX Model).

The crystalline structure of samples was characterized using X-ray (XRD) diffractometer (Schimadzu 7000, Japan) operating with $\mathrm{Cu} \mathrm{K \alpha}$ radiation $(\lambda=0.154060 \mathrm{~nm})$ generated at $30 \mathrm{kV}$ and $30 \mathrm{~mA}$ with scanning rate of $4^{\circ}$ min-1 for $2 \theta$ values between 10 and 80 degrees. Raman measurement was carried out with BRUKER SENNTRRY, Micro Raman spectroscopy operating at $532 \mathrm{~nm}$ laser, and embedded wavelength 88 to $4000 \mathrm{~cm}^{-1}$ spectral range and up to $3 \mathrm{~cm}^{-1}$ resolution.

A Fourier-transform infrared spectroscopy (JASCO FTIR 6100 spectrometer, 64 scans with $4 \mathrm{~cm}^{-1}$ resolution) was employed to demonstrate the chemical composition of nanomaterials in the range of $4000-400 \mathrm{~cm}^{-1}$.

\section{Results and Discussion}

The XRD patterns of the pure MWCNTs and the MWCNTs/ZnO (99:1 $\mathrm{wt} \%$ ) nanocomposites are shown in Fig. 1. From Fig.1, the characteristic peak at $2 \theta=26^{\circ}$ and $43^{\circ}$ represents graphite peak that corresponding to the carbon of the MWCNTs and reveals the crystallinity of the MWCNTs ${ }^{(9)}$. Moreover, the diffractions of both MWCNTs and ZnO with ratio of (99:1 wt\%) clearly observed that other peaks are appeared in the profile rather than the peak corresponding to the $\mathrm{C}$ of the MWCNTs at $26^{\circ}$, these peaks reveal a good agreements with $\mathrm{ZnO}$ (JCPDS 36-1451).

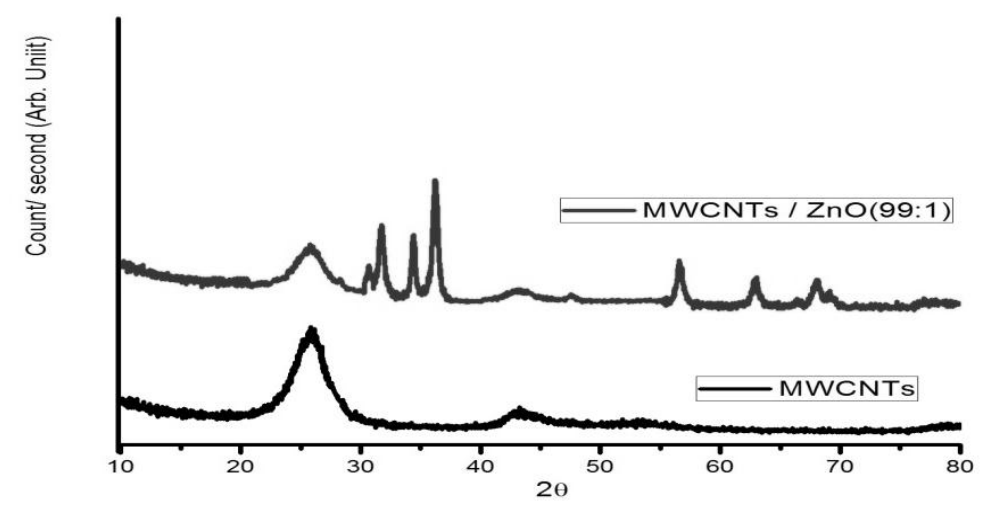

Fig. 1. XRD patterns of MWCNTs and MWCNTs /ZnO nanocomposites.

Egypt. J. Chem. 59, No. 6 (2016) 
The main dominant peaks for $\mathrm{ZnO}$ were identified at $2 \theta=31.75^{\circ}, 34.41^{\circ}$, $36.20^{\circ}, 47.47^{\circ}, 56.45^{\circ}, 62.72^{\circ}, 66.25^{\circ}, 67.85^{\circ}$ and $68.91^{\circ}$, that could be indexed as (100), (002), (101), (102), (110), (103), (200), (112), (201) planes of $\mathrm{ZnO}$ nanoparticles, respectively ${ }^{(10)}$. There were not any other diffraction peaks observed related to any impurities, it means that the resulted MWCNTs/ZnO nanocomposite was pure.

The diameter (D) of $\mathrm{ZnO}$ nanoparticles was calculated using Debye Scherrer formula $\mathrm{D}=\mathrm{K} \lambda /(\beta \cos \theta)$, where $\mathrm{K}$ is the Scherrer constant (equal to 0.9$), \beta$ is the peak width at half maximum, $\lambda$ is the X-ray wave length and $\theta$ is the Bragg diffraction angle ${ }^{(11)}$. The XRD pattern peaks showed that the $\mathrm{ZnO}$ nanoparticles had a diameter of about $7 \mathrm{~nm}$. Furthermore, the dominant peaks of $\mathrm{ZnO}$ were more intensive and narrower, which means that a good crystalline nature of the $\mathrm{ZnO}$ has been grown on the surface of MWCNTs.

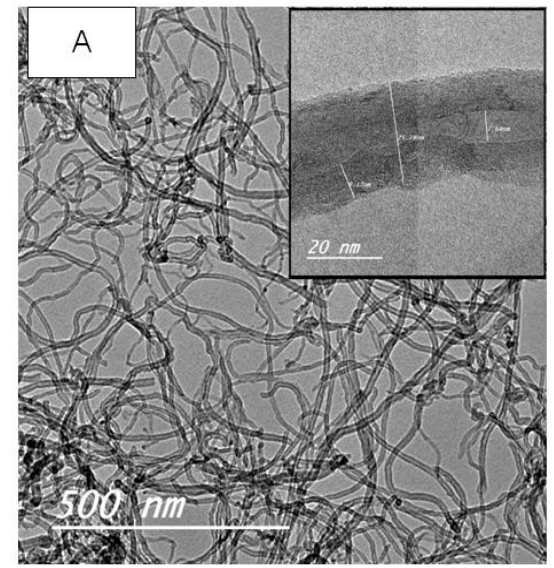

Fig. 2. HRTEM of (a) MWCNTs nanocomposite.

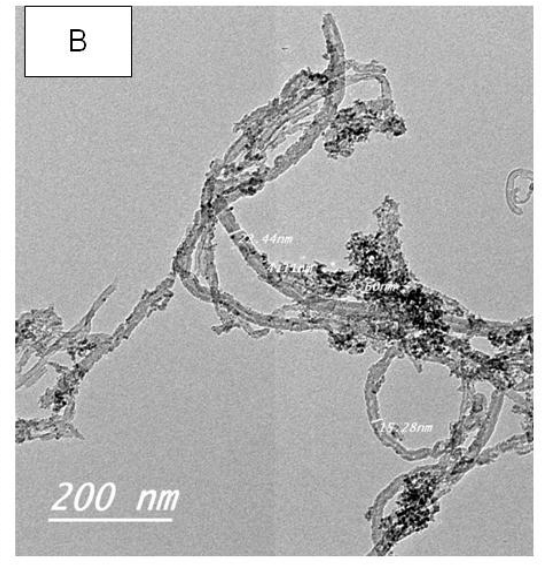

and (b) MWCNTs/ZnO (99:1 wt\%)

Figure 2(a) displays TEM images of the typical morphology of MWCNTs prior to deposition indicating that most of the nanotubes are multiwalled tubes, while Fig. 2(b) showed the morphology of decorated MWCNTs/ ZnO (99:1) nanocomposite indicating that the deposition of $\mathrm{ZnO}$ nanocrystals is uniformed distribution along the walls of the tubes with an average diameter around 2-7 $\mathrm{nm}$ and this result is in a good agreement with the result obtained from XRD.

As shown in Fig. 3, typical FTIR spectra of MWCNTs and MWCNTs/ZnO nanocomposites can be clarify briefly. There is a band at $1569.5 \mathrm{~cm}^{-1}$ is associated with the vibration of the carbon skeleton of the carbon nanotubes. The two bands at about 2368.7 and $2337.6 \mathrm{~cm}^{-1}$ are corresponding to the $\mathrm{C}=\mathrm{C}$ double bonds stretch vibration, originated from the surface of tubes ${ }^{(12)}$. 


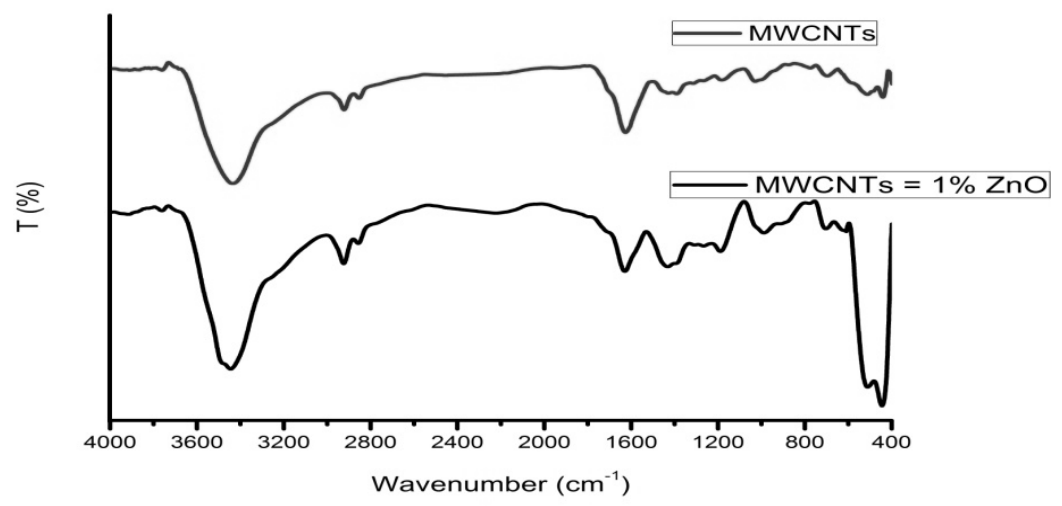

Fig. 3. FT-IR spectra of MWCNTs and MWCNTs/ZnO (99:1 wt\%) nanocomposite.

The two bands at $1706,1130 \mathrm{~cm}^{-1}$ indicate the existence of carboxylic groups on the tubes surface ${ }^{(13)}$. While IR spectra of the resulted MWNTs/ZnO nanocomposites reveal the different surface chemistry of MWCNTs and the MWNTs/ZnO nanocomposites. It can be observed that there are another two weak peaks around 3516 and $3948 \mathrm{~cm}^{-1}$, which can be assigned to the stretching vibrations of $\mathrm{OH}$ groups ${ }^{(14-16)}$. Compared with the IR spectra of MWCNTs, the two peaks at 2368 and $2337 \mathrm{~cm}^{-1}$ became narrower and the two bands around $1706,1130 \mathrm{~cm}^{-1}$ are lower in the composite than those of pure MWCNTs. The result suggested that the surface of MWCNTs has been covered almost of surface active sites by $\mathrm{ZnO}$. Furthermore, the peak observed at about $460 \mathrm{~cm}^{-1}$ in Fig. 3 is assigned to the formation of $\mathrm{ZnO}$.

Figure 4 shows the typical FESEM images of MWCNTs/ZnO nanocomposites. In Fig. 4(a), the walls are composed of graphite sheets aligned to the tube axis. The structures of individual MWCNTs are middle hollow, while in Fig. 4(b) it is shown that $\mathrm{ZnO}$ nanoparticles have grown as a thin nanosheet film layer on the surface of the MWCNTs because the diameter of the tubes increase a few tens in nanometer.
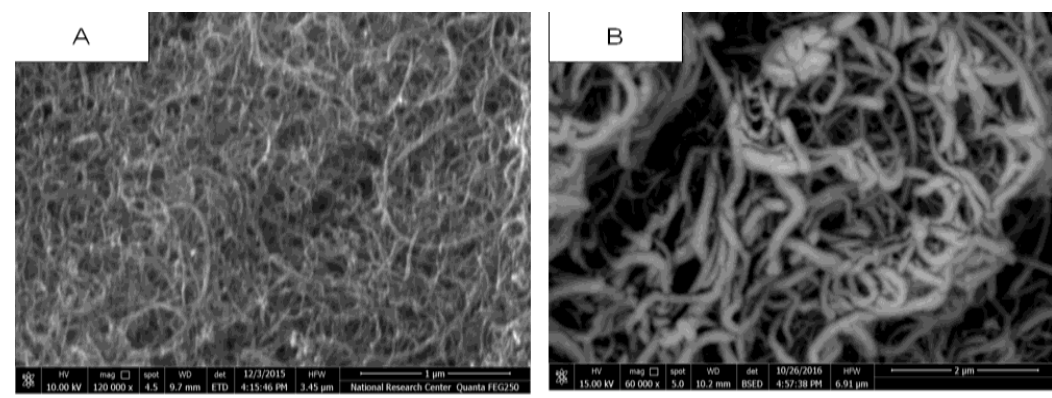

Fig.4. FESEM of (a) MWCNTs and (b) MWCNTs/ZnO (99:1 wt\%) nanocomposite. 


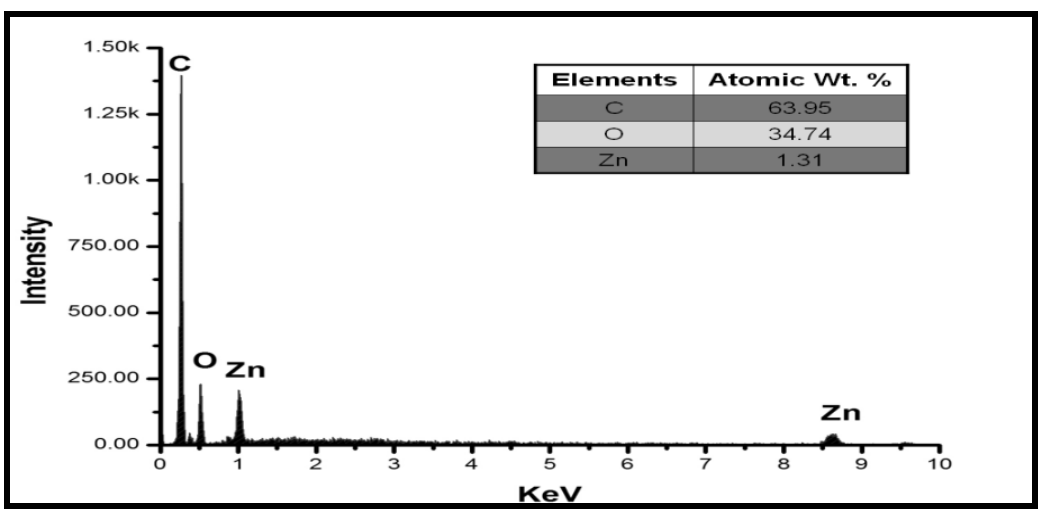

Fig. 5. EDX of MWCNTs/ZnO (99:1 wt\%) nanocomposite.

In Fig. 5, EDX analysis was performed in order to confirm the elements which presented in the resulted MWCNTs/ZnO nanocomposite, and the analysis reveals the presence of $\mathrm{Zn}, \mathrm{O}$ and $\mathrm{C}$ which emphasize the successful of decoration process with $\mathrm{ZnO}$ nanoparticles. Also it was noted that there is no any remaining catalyst in the composite improving the successful purification process of the MWCNTs.

\section{Conclusion}

In summary, MWCNTs/ZnO (99:1 wt\%) nanocomposite had been successfully synthesized via a sol-gel method. TEM micrographs confirmed that nanocomposite which is composed of carbon nanotubes coated evenly by $\mathrm{ZnO}$ particles with a particle size of $\mathrm{ZnO}$ ranging from $2-7 \mathrm{~nm}$ and this result was supported by the results obtained from XRD analysis. The morphology of nanocomposite demonstrates that $\mathrm{ZnO}$ had grown on the walls of MWCNTs as uniformed layer in the shape of thin film layer of noanspheres covering the surface of the tubes. Also it was proved from EDX analysis that the resulted nanocomposite was pure.

\section{References}

1. Milunovic, S., and Roy, M.A.J., An Introduction to Nanotechnology: The Next Small Thing, Merrill Lynch (2001).

2. Iijima, S., Helical microtubules of graphitic carbon. Nature, 354(6348), 56-58 (1991).

3. Zhang, Y., Zhang, Q., Li, Y. B., Wang, N., and Zhu, J., Coating of carbon nanotubes with tungsten by physical vapor deposition. Solid State Communications, 115 (1), 51-55 (2000).

4. Hongwei Bai, Xiaoli Zan, Lilin Zhang and Darren Delai Sun, Multifunctional $\mathrm{CNT} / \mathrm{ZnO} / \mathrm{TiO}_{2}$ nanocomposite membrane for concurrent filtration and photocatalytic degradation, Separation and Purification Technology, 156, Part 3, 922-930 (2015).

Egypt. J. Chem. 59, No. 6 (2016) 
5. Georgakilas, V., Gournis, D., Tzitzios, V., Pasquato, L., Guldie, D.M. and Prato, M., Decorating carbon nanotubes with metal or semiconductor nanoparticles. J. Mater. Chem. 17, 2679-2694 (2007).

6. Ye, X. R., Lin, Y. and Wai, C. M., Decorating catalytic palladium nanoparticles on carbon nanotubes in supercritical carbon dioxide. Chem. Commun. 9, 642 (2003).

7. Ji Qi, Neeva Benipal, Changhai Liang and Wenzhen Li, PdAg/CNT catalyzed alcohol oxidation reaction for high-performance anion exchange membrane direct alcohol fuel cell (alcohol = methanol, ethanol, ethylene glycol and glycerol). Applied Catalysis B: Environmental, 199, 494-503 (2016).

8. Chien-Sheng Huang, Chun-Yu Yeh, Yung-Huang Chang, Yi-Min Hsieh, Chien-Yeh Ku and Quan-Ting Lai, Field emission properties of CNT$\mathrm{ZnO}$ composite materials. Diamond and Related Materials, 18(2-3), 452-456 (2009).

9. Papitchaya Woointranont and Wisanu Pecharapa, Effects of Surface Modification of Carbon Nanotubes on the Deposition of NiO/CNTs Nanocomposites. Journal of the Microscopy Society of Thailand, 4(2), 116-119 (2011).

10. Pooya Azadi, Ramin Farnood and Emanuel Meier, Preparation of Multiwalled Carbon Nanotube-Supported Nickel Catalysts Using Incipient Wetness Method. J. Phys. Chem. A, 114, 3962-3968 (2010).

11. Jayaprakash Khanderi, Rudolf C. Hoffmann and Jorg J. Schneider, A 3D monolithic CNT block structure as a reductant, support and scavenger for nanoscopic gold, platinum and zinc oxide. Nanoscale, 2, 613-622 (2010).

12. Kuo-Yuan Hwa and Boopathi Subramani, Synthesis of zinc oxide nanoparticles on graphene-carbon nanotube hybrid for glucose biosensor applications. Biosensors \& Bioelectronics, 62, 127-133 (2014).

13. Hamadanian,M., Jabbari,V., Shamshiri,M., Asad,M. and Mutlay,I., Preparation of novel hetero-nanostructures and high efficient visible light-active photocatalyst using incorporation of CNT as an electron-transfer channel into the support $\mathrm{TiO}_{2}$ and PbS. Journal of the Taiwan Institute of Chemical Engineers, 44, 748-757 (2013).

14. Xiaoya Yuan, Chao Zhou, Qiuye Jing, Qi Tang, Yuanhua Mu and An-ke Du, Facile Synthesis of $\mathrm{g}_{-} \mathrm{C}_{3} \mathrm{~N}_{4}$ Nanosheets/ZnO Nanocomposites with Enhanced Photocatalytic Activity in Reduction of Aqueous Chromium(VI) under Visible Light. Nanomaterials, 6, 173 (2016).

15. Alagar Ramar, Thiagarajan Soundappan, Shen-Ming Chen, Muniyandi Rajkumar and Saraswathi Ramiah, Incorporation of Multi-Walled Carbon Nanotubes in $\mathrm{ZnO}$ for Dye Sensitized Solar Cells. Int. J. Electrochem. Sci., 7, 11734 - 11744 (2012).

16. Chunyang Zhang, Yahong Xie, Junhong Ma, Jing Hu, Cancan Zhang, Composite Catalyst of Reduced $\mathrm{Black}_{\mathrm{TiO}_{2}-\mathrm{x}}$ /CNT: Highly Efficient Counter Electrode for ZnO-Based Dye-Sensitized Solar Cells. ChemComm., 00, 1-3 (2015).

(Received 22/11/2016; accepted 30/11/2016) 
تحضير وتوصيف متراكب من انابيب الكريون النانومترية المطعم باكسيد الزنك

ايمان عبدالصادق احمد مو افي' ، ماجده ضوي بدري" ، احمد صبحي محمد مرسي² ،

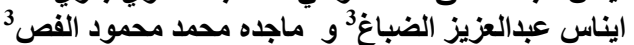

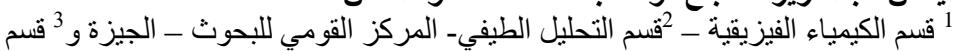
الكيمياء - كلية العلوم - جامعة الأز هر - القاهرة - مصر.

تم تحضير مثر اكب من انابيب الكربون النانومترية المطعم باكسيد الزنكا بطريفة المحلول

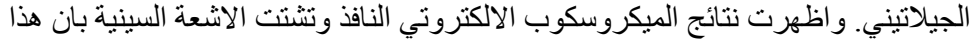

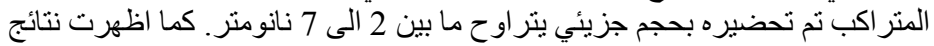

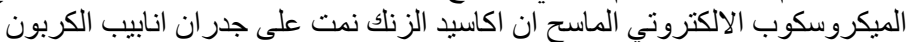

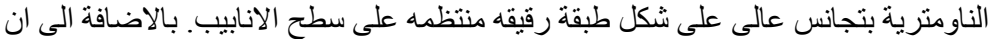

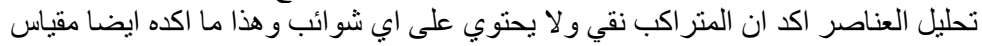

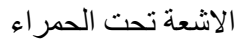

